\title{
Carbohydrate Moiety of von Willebrand Factor Is Not Necessary for Maintaining Multimeric Structure and Ristocetin Cofactor Activity but Protects from Proteolytic Degradation
}

\author{
Augusto B. Federici, John H. Elder, Luigi De Marco, \\ Zaverio M. Ruggeri, and Theodore S. Zimmerman \\ Departments of Basic and Clinical Research and of Immunology; \\ Department of Molecular Biology, Scripps Clinic and Research \\ Foundation, La Jolla, California 92037; Centro \\ Immunotrasfusionale, Ospedale Civile, Pordenone, Italy
}

bstract. To better define the role of carbohydrate in the structure and ristocetin cofactor activity of von Willebrand factor, we have removed up to $83 \%$ of total hexose by sequential treatment of the molecule with endo- $\beta$ - $N$-acetyl-glucosaminidase $\mathrm{F}$ (endo $\mathrm{F}$ ), neuraminidase, and $\beta$-galactosidase. Endo $\mathrm{F}$ alone removed $69 \%$ of total hexose and D-galactose, and $71 \%$ of sialic acid. However, there was no discernible loss of large multimers and the ristocetin cofactor activity was decreased by only $11 \%$. The reduced von Willebrand factor subunit migrated more rapidly in polyacrylamide gels containing SDS, consistent with a $10 \%$ decrease of molecular mass. All multimers of unreduced carbohydrate-modified von Willebrand factor migrated more rapidly in SDS-agarose, but the triplet pattern of individual multimers was unchanged. This alteration in multimer migration rate did not resemble alterations found so far in von Willebrand disease variants. Further treatment of von Willebrand factor with neuraminidase and $\beta$-galactosidase reduced the D-galactose to $15 \%$ and ristocetin cofactor activity to $57 \%$. A similar decrease in ristocetin cofactor activity was seen if von Willebrand factor was treated only with neuraminidase and $\beta$ galactosidase. In contrast, treating von Willebrand factor

This paper was presented in part at the XXV Meeting of the American Society of Hematology, San Francisco, 1983, and published in abstract form in Blood (November 1983, Supplement).

Address reprint requests to Dr. Zimmerman, Scripps Clinic and Research Foundation.

Received for publication 30 January 1984 and in revised form 27 July 1984.

J. Clin. Invest.

(c) The American Society for Clinical Investigation, Inc. 0021-9738/84/12/2049/07 \$1.00

Volume 74, December 1984, 2049-2055 with neuraminidase and $\beta$-galactosidase in the presence of protease inhibitors $(20 \mathrm{mM}$ benzamidine, $20 \mathrm{U} / \mathrm{ml}$ aprotonin, $15 \mu \mathrm{g} / \mathrm{ml}$ leupeptin) resulted in a comparable removal of carbohydrate with no change in ristocetin cofactor activity. Moreover, the multimeric structure remained intact in spite of $80 \%$ removal of D-galactose. This suggested that carbohydrate was protecting von Willebrand factor against traces of one or more protease contaminants. Evidence in support of this hypothesis was obtained by exposing von Willebrand factor to plasmin after pretreatment with neuraminidase alone or with neuraminidase and $\beta$-galactosidase. A loss of large multimers was observed from von Willebrand factor that had been pretreated with neuraminidase, but this was even greater if pretreatment was also with $\beta$-galactosidase. In contrast, the multimeric structure of von Willebrand factor with intact carbohydrate was not affected by plasmin under similar conditions. These studies suggest that carbohydrate protects von Willebrand factor from disaggregation occurring secondarily to proteolytic attack but does not play a direct role in maintaining its multimeric structure or ristocetin cofactor activity.

\section{Introduction}

von Willebrand Factor (vWF) ${ }^{1}$ is a large multimeric glycoprotein that interacts with platelets at the early stages of hemostasis.

1. Abbreviations used in this paper: EACA, $\epsilon$-amino caproic acid; endo $\mathrm{F}$, endo- $\beta$ - $N$-acetyl-glucosaminidase F; TBS, Tris-buffered saline; vWF, von Willebrand factor; eF-vWF, vWF modified by endo F; neu-vWF, $v W F$ modified by neuraminidase; neu- $\beta$-gal-vWF, vWF modified by neuraminidase and $\beta$-galactosidase sequentially; ef-neu-vWF, vWF modified by endo $F$ and neuraminidase sequentially; eF-neu- $\beta$-gal$v W F$, vWF modified by endo $F$, neuraminidase, and $\beta$-galactosidase sequentially. 
The largest vWF multimers appear to be the most hemostatically effective and are absent in some variants of von Willebrand disease (1-4). Carbohydrate composes $10-15 \%$ of the mass of $\mathrm{vWF}$ and has been implicated in the structural and functional integrity of the molecule (1). The structure of the major asparagine-linked sugar chain of vWF has been determined (5). The removal of terminal sialic acid with neuraminidase has been reported to result in loss of ristocetin cofactor activity by some authors $(6,7)$, while other investigators have found no changes of this activity $(8,9)$. Rather, asialo-vWF induces spontaneous aggregation of platelets in the presence of one or more plasma cofactors (8). Removal of the penultimate galactose by $\beta$-galactosidase or its modification by galactose-oxidase has been reported to largely abolish the ristocetin cofactor activity of vWF $(9,10)$. More recently, removal of galactose residues has also been associated with loss of large vWF multimers (11). Carbohydrate analysis of vWF from patients with von Willebrand disease has shown decreased sugar content in some individuals $(8,12,13)$, but not in others $(8,14)$.

We have treated vWF sequentially with endo- $\beta-N$-acetylglucosaminidase $F$ (endo $F$ ) (15), neuraminidase, and $\beta$-galactosidase, and were able to remove as much as $83 \%$ of the carbohydrate from the molecule. However, we could not confirm that carbohydrate was necessary for either the ristocetin cofactor activity of vWF or its multimeric structure. Rather we demonstrated that carbohydrate protects vWF against plasmin degradation. The role of the carbohydrate side chain in protecting glycoproteins from proteolytic degradation has been observed previously (16) and may be of importance in maintaining the integrity of $\mathrm{vWF}$ in an environment where proteases, such as plasmin, may be present.

\section{Methods}

vWF protein was purified from cryoprecipitate, kindly provided by Dr. Carolyn Orthner (American Red Cross, Bethesda, MD). This material was recryoprecipitated after the addition of $20 \mathrm{mM} \epsilon$-aminocaproic acid (EACA) and processed according to the method of Newman et al. (17), as modified by Switzer and McKee (18). After the final polyethylene glycol precipitation, sucrose $(20 \% \mathrm{wt} / \mathrm{vol})$ was added and ultracentrifugation was performed at $100,000 \mathrm{~g}$ for $45 \mathrm{~min}$. The lipid was removed by aspiration and the remaining supernatant was then passed through a $90 \times 5-\mathrm{cm}$ Sepharose CL-4B (Pharmacia Fine Chemicals, Piscataway, NJ) column equilibrated with $0.02 \mathrm{M}$ imidazol, $0.01 \mathrm{M}$ citrate, $0.02 \mathrm{M}$ EACA, $0.15 \mathrm{M} \mathrm{NaCl}, \mathrm{pH}$ 6.5.

Fractions of the first two-thirds of the void volume were pooled and concentrated to $1-4 \mathrm{mg} / \mathrm{ml}$ in dialysis bags using Aquacide II-A (Calbiochem-Behring Corp., La Jolla, CA) as a hygroscopic agent. The vWF was then extensively dialyzed against $0.02 \mathrm{M}$ Tris, $0.15 \mathrm{M} \mathrm{NaCl}$, pH 7.4 (Tris-buffered saline, TBS). After reduction and electrophoresis in a $5 \%$ polyacrylamide gel containing SDS, only one major polypeptide of $M_{\mathrm{r}}=200,000$ could be detected by Coomassie Blue staining. Endo $F$ was prepared from Flavobacterium meningosepticum and purified as described (15). Neuraminidase from Vibrio cholerae was obtained from Calbiochem-Behring Corp., and $\beta$-galactosidase from Streptococcus pneumoniae was kindly provided by Dr. Gilbert Ashwell (National
Institutes of Health, Bethesda, MD). Plasmin was a gift of Dr. David Loskutoff (Scripps Clinic and Research Foundation, La Jolla, CA) and was prepared as follows: plasminogen $(900 \mu \mathrm{g} / \mathrm{ml})$ was purified from plasma as described (19) and activated to plasmin by incubating it with urokinase $(190 \mu \mathrm{g} / \mathrm{ml})$ for $24 \mathrm{~h}$ at $37^{\circ} \mathrm{C}$ in a $0.1 \mathrm{M}$ Tris- $\mathrm{HCl}$ buffer, pH 8.1, containing $50 \%$ glycerol.

vWF was incubated with endo $F$ for $18 \mathrm{~h}$ at $37^{\circ} \mathrm{C}$ after dialysis into $0.1 \mathrm{M}$ phosphate buffer, pH 6.1, containing $50 \mathrm{mM}$ EDTA. For most experiments, $50 \mathrm{U}$ of enzyme/mg of vWF were used $(1 \mathrm{U}$ of endo $F$ is the amount necessary to convert $1 \mathrm{nmol}$ of ribonuclease $B$ to ribonuclease $\mathrm{A}$ in $1 \mathrm{~h}$ at $37^{\circ} \mathrm{C}$ ). If the vWF was then to be treated with exoglycosidase, it was passed through a $15 \times 0.5-\mathrm{m}$ Sepharose CL-4B column equilibrated with the appropriate buffer before treatment with each enzyme. Neuraminidase was incubated at a concentration of $0.1 \mathrm{U} / \mathrm{mg}$ of $\mathrm{vWF}$, in the presence of $8 \mathrm{mM} \mathrm{CaCl}_{2}$, for $3 \mathrm{~h}$ at $37^{\circ} \mathrm{C}$, $\mathrm{pH} 6.5$, and $\beta$-galactosidase was incubated at a concentration of 0.01 $\mathrm{U} / \mathrm{mg}$ of vWF, for $24 \mathrm{~h}$ at $37^{\circ} \mathrm{C}, \mathrm{pH} 6.1$. As a control, native vWF was incubated under the same conditions but in the absence of the enzymes. Results obtained with this control vWF did not differ from those obtained with vWF that had not been so incubated. In some experiments, digestion with neuraminidase and $\beta$-galactosidase was carried out with benzamidine $(20 \mathrm{mM})$, leupeptin $(15 \mu \mathrm{g} / \mathrm{ml})$ and aprotinin $(20 \mathrm{U} / \mathrm{ml})$ inluded in all buffers.

After incubation with the enzymes, vWF was passed through a 15 $\times 0.5-\mathrm{cm}$ Sepharose CL-4B column equilibrated with TBS. Control native $\mathrm{vWF}$ was similarly treated. Void volume fractions were pooled and analyzed within $24 \mathrm{~h}$ for carbohydrate content, ristocetin cofactor activity, and mobility in both unreduced SDS-agarose gels and reduced SDS-polyacrylamide gels. The recovery of VWF in the void volume fractions was always between 50 and $70 \%$. In some experiments, the carbohydrate present in the included fractions was measured to demonstrate that carbohydrate removed from vWF could be recovered.

In some experiments, vWF was subsequently incubated with plasmin in concentrations of 4 to $96 \mu \mathrm{g} / \mathrm{mg}$ of vWF for $4-24 \mathrm{~h}$ at $37^{\circ} \mathrm{C}$. After incubation, plasmin was neutralized with aprotonin $(20-50 \mathrm{U} / \mathrm{ml})$.

Total hexose content of vWF was measured by the phenol sulphuric method of Dubois et al. (20), using a 1:1 mixture of glucose and galactose or a 1:1 mixture of mannose and galactose as reference standards. Both standards gave similar results. $N$-Acetyl glucosamine was determined in a Beckman (Beckman Instruments, Fullerton, CA) amino acid analyzer $121-\mathrm{M}$ after hydrolysis in $5.7 \mathrm{~N} \mathrm{HCl}$ at $110^{\circ} \mathrm{C}$ for $4 \mathrm{~h}$, using pure $\mathrm{N}$-acetyl glucosamine as reference. Sialic acid was measured after hydrolysis of vWF in $0.02 \mathrm{M} \mathrm{H}_{2} \mathrm{SO}_{4}$ at $80^{\circ} \mathrm{C}$ for 60 min using $\mathrm{N}$-acetylneuraminic acid as a standard (21). D-Galactose and L-Fucose were determined after hydrolysis in 1 or $2 \mathrm{M}$ hydrochloric acid at $100^{\circ} \mathrm{C}$ for $2 \mathrm{~h}$ by an enzymatic assay using galactose- and fucose-dehydrogenase respectively. No differences were seen at the different hydrochloric acid concentrations (22).

Protein concentration was determined either by the method of Lowry et al. (23) or by absorbance at $280 \mathrm{~nm}$, using a scattering correction based on the absorbance at $320 \mathrm{~nm}$ (18). Both methods gave similar values and the results obtained by the latter method are given.

SDS-polyacrylamide slab gel electrophoresis of reduced vWF was performed according to the method of Laemmli (24). Reduction was accomplished with either $50 \mathrm{mM}$ DTT or $2 \% \beta$-mercaptoethanol. Gels were stained with Coomassie Blue. Molecular weight standards were reduced fibronectin $\left(M_{\mathrm{r}}=220,000\right)$, phosphorylase b $\left(M_{\mathrm{r}}=95,000\right)$, and bovine serum albumin $\left(M_{\mathrm{r}}=68,000\right)$.

SDS-agarose gel electrophoresis of unreduced vWF was performed 
Table I. Carbohydrate Content of Native and Carbohydrate Modified vWF (nmol/mg)

\begin{tabular}{|c|c|c|c|c|c|}
\hline Type of vWF & $\begin{array}{l}\text { Total hexose } \\
\text { Mean (range) }\end{array}$ & $\begin{array}{l}N \text {-Acetyl glucosamine } \\
\text { Mean (range) }\end{array}$ & $\begin{array}{l}\text { Sialic acid } \\
\text { Mean (range) }\end{array}$ & $\begin{array}{l}\text { L-Fucose } \\
\text { Mean (range) }\end{array}$ & $\begin{array}{l}\text { D-Galactose } \\
\text { Mean (range) }\end{array}$ \\
\hline $\begin{array}{c}\text { Native } \\
(9) \S\end{array}$ & $\begin{array}{l}788 \quad 810^{*} \\
(718-888)\end{array}$ & $\begin{array}{l}259 \ddagger \\
(240-273)\end{array}$ & $\begin{array}{l}132 \\
(116-166)\end{array}$ & $\begin{array}{l}70 \ddagger \\
(56-89)\end{array}$ & $\begin{array}{l}181 \\
(135-258)\end{array}$ \\
\hline $\begin{array}{l}\mathrm{Neu} \\
(8)\end{array}$ & $\begin{array}{l}648 \\
(639-658)\end{array}$ & - & $\begin{array}{l}5 \\
(3-8)\end{array}$ & - & $\begin{array}{l}178 \\
(135-205)\end{array}$ \\
\hline $\begin{array}{l}\text { Neu- } \beta \text {-gal } \\
\text { (4) }\end{array}$ & $\begin{array}{ll}535 & 490^{*} \\
(515-559) & \end{array}$ & - & $\begin{array}{l}5 \\
(3-6)\end{array}$ & - & $\begin{array}{ll}51 & 40^{*} \\
(20-68) & \end{array}$ \\
\hline $\begin{array}{l}\mathrm{eF} \\
\quad(8)\end{array}$ & $\begin{array}{l}245 \\
(208-290)\end{array}$ & $\begin{array}{l}51 \\
(44-58)\end{array}$ & $\begin{array}{l}38 \\
(18-58)\end{array}$ & $\begin{array}{l}66 \\
(50-85)\end{array}$ & $\begin{array}{l}56 \\
(44-78)\end{array}$ \\
\hline $\begin{array}{c}\text { eF-neu } \\
(7)\end{array}$ & $\begin{array}{l}204 \\
(189-220)\end{array}$ & - & $<5$ & - & $\begin{array}{l}54 \\
(36-78)\end{array}$ \\
\hline $\begin{array}{l}\text { eF-neu- } \beta \text {-gal } \\
\text { (3) }\end{array}$ & $\begin{array}{l}134 \\
(123-141)\end{array}$ & - & $<5$ & - & $\begin{array}{l}27 \\
(12-44)\end{array}$ \\
\hline
\end{tabular}

* These values were obtained when treatment with exoglycosidases was performed in the presence of benzamidine (20 mM), leupeptin (15 $\mu \mathrm{g} /$ $\mathrm{ml})$, and aprotonin $(20 \mathrm{U} / \mathrm{ml}) . \quad \ddagger n=3$. $\S$ Number of experiments indicated in parentheses.

as previously described (25), except that $1.4 \%$ LGT-agarose (Sigma Chemical Co., St. Louis, MO) was used.

Ristocetin cofactor activity was measured as published (26) except that formalin fixed platelets were used. vWF antigen levels were analyzed by rocket immunoelectrophoresis (27). In both assays results were expressed as a percent of a pool of 20 normal plasmas.

\section{Results}

Carbohydrate content after enzymatic treatment. Endo $\mathrm{F}$ removes carbohydrate most efficiently with the aid of detergents and reducing agents (15). However, for our studies, we wished to maintain as much native structure as possible and thus such agents were not used. Therefore, relatively large quantities of enzyme were required. To determine the maximum amount of carbohydrate that could be removed with endo $F$, increasing concentrations of the enzyme were incubated with a constant concentration of vWF. At $50 \mathrm{U}$ endo $\mathrm{F} / \mathrm{mg}$ of $\mathrm{vWF}$, maximal removal of hexose, sialic acid, and D-galactose was achieved. For all succeeding experiments, this concentration of endo $F$ was, therefore, used. Approximately $69 \%$ of total hexose was removed from endo F-treated vWF (eF-vWF) (Tables I and II), as were corresponding amounts of $N$-acetyl glucosamine, sialic acid and D-galactose (Tables I and II). However, there was only a minimal decrease in the content of $L$-fucose (Tables I and II), consistent with extensive fucosylation of the innermost $\mathrm{N}$-acetylglucosamine of the chitobiose core that remains after endo $F$ treatment $(5,14)$. Treatment of eF-vWF with neuraminidase and $\beta$-galactosidase resulted in a molecule (eF-neu-
$\beta$-gal-vWF), which contained $<4 \%$ sialic acid, $15 \%$ D-galactose, and $17 \%$ of the total hexose of native vWF (Tables I and II).

Native vWF was also treated with neuraminidase (neuvWF), then followed by $\beta$-galactosidase (neu- $\beta$-gal-vWF). In four experiments, this resulted in an average reduction of sialic acid to $5 \%$, D-galactose to $28 \%$, and total hexose to $68 \%$ of the initial concentrations (Tables I and II). When benzamidine, leupeptin, and aprotinin were included in all buffers, a similar reduction in carbohydrate was seen (Tables I and II). Carbohydrate removed by the glycosidases could be recovered in the included volume of the Sepharose CL-4B column used to separate the glycosidase from the deglycosylated vWF.

Structure and function of carbohydrate modified $v W F$. Polyacrylamide (5\%) gel electrophoresis of reduced eF-vWF in

Table II. Percent Carbohydrate Remaining in Modified $v W F$

\begin{tabular}{|c|c|c|c|c|c|}
\hline Type of vWF & Total hexose & $\begin{array}{l}N \text {-Acetyl } \\
\text { glucosamine }\end{array}$ & $\begin{array}{l}\text { Sialic } \\
\text { acid }\end{array}$ & L-Fucose & D-Galactose \\
\hline Native & 100 & 100 & 100 & 100 & 100 \\
\hline $\mathrm{Neu}$ & 82 & - & 5 & - & 98 \\
\hline Neu- $\beta$-gal & $6860^{*}$ & - & 5 & - & $28 \quad 20^{*}$ \\
\hline eF & 31 & 20 & 29 & 94 & 31 \\
\hline eF-neu & 26 & - & $<4$ & - & 30 \\
\hline eF-Neu- $\beta$-gal & 17 & - & $<4$ & - & 15 \\
\hline
\end{tabular}

* These values were obtained when treatment with exoglycosidases was performed in the presence of benzamidine $(20 \mathrm{mM})$, leupeptin $(15 \mu \mathrm{g} / \mathrm{ml})$ and aprotonin $(20 \mathrm{U} / \mathrm{ml})$. 
the presence of $0.1 \%$ SDS showed a major subunit of about $M_{\mathrm{r}}=180,000$ compared with $M_{\mathrm{r}}=200,000$ for native $\mathrm{vWF}$, suggesting a decrease in molecular mass of about $10 \%$ (Fig. 1). A similar increased mobility was observed with eF-neu- $\beta$-galvWF (not shown). A faint band was present beneath the major band of native or glycosidase-treated vWF. This material was shown to be antigenically related to VWF by electrophoretic transfer to nitrocellulose and reaction with monoclonal antibodies to vWF (Western blotting) (28). Though not always apparent by Coomassie staining, it was always detected by monoclonal antibody and presumably represents a proteolytic product of the major subunit.

Unreduced eF-neu- $\beta$-gal-vWF and neu- $\beta$-gal-vWF were electrophoresed in SDS-agarose gels and compared with native vWF (Fig. 2). The sample treated only with exoglycosidases

\section{Nat eF}

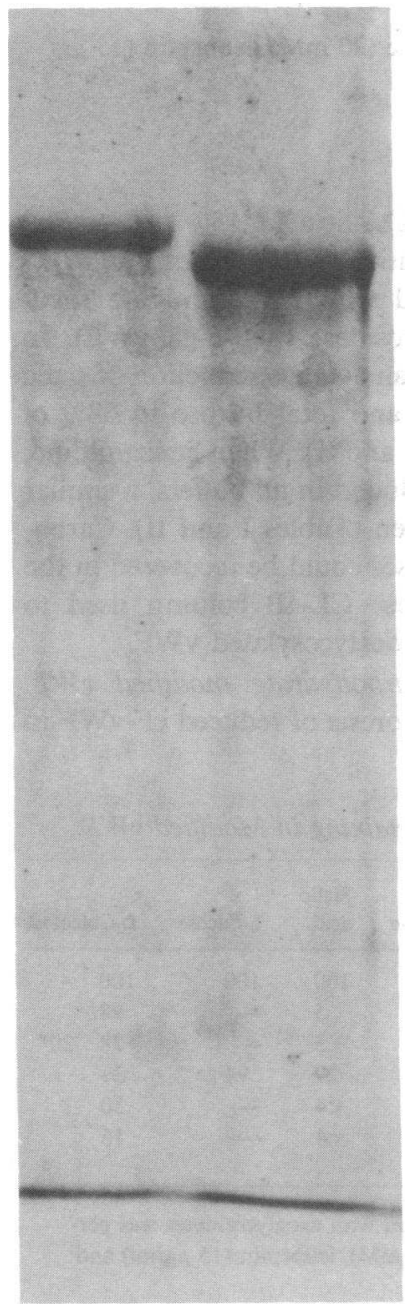

Figure 1. SDS-polyacrylamide gel electrophoresis of reduced native (Nat) or eF vWF. Approximately $6 \mu \mathrm{g}$ was applied per lane. The gel was stained with Coomassie Blue.

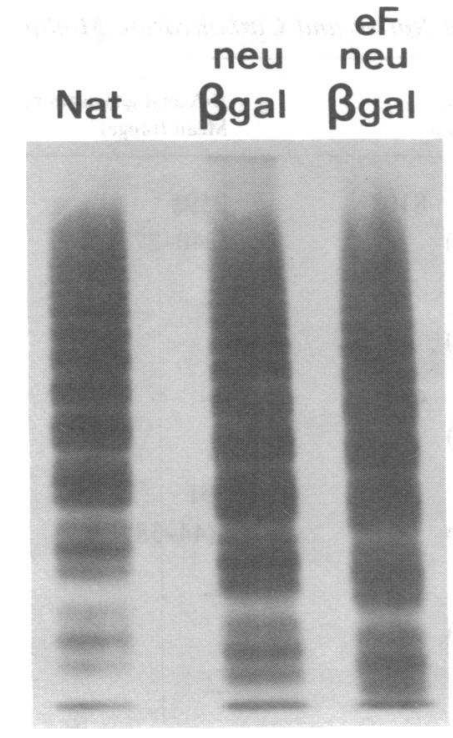

Figure 2. SDS-1.4\% agarose electrophoresis of unreduced native (Nat) vWF, or vWF treated sequentially with neuraminidase followed by $\beta$-galactosidase (neu- $\beta$-gal), or with endo $F$ followed by neuraminidase and $\beta$-galactosidase (eFneu- $\beta$-gal). Approximately 10 ng were applied. Following fixation with isopropanol and acetic acid, the gels were treated with ${ }^{125}$ I-anti-vWF. An autoradiograph of the gel is shown.

showed increased electrophoretic mobility when compared with native vWF. This was even greater if the vWF was first treated with endo $F$. Endo $F$ alone had a similar effect (not shown). However, no apparent changes in the triplet structure nor evident loss of the largest multimers occurred after removal of carbohydrate. Purified native vWF had the same multimeric structure as VWF in plasma (not shown).

Ristocetin cofactor activity per unit of VWF antigens was determined for the different forms of carbohydrate modified vWF (Table III). eF-vWF showed $89 \%$ of initial activity, while eF-neu-vWF and eF-neu- $\beta$-gal-vWF had 70 and $57 \%$, respectively. Ristocetin cofactor activity of neu-vWF was higher than that of native vWF (111\%), while that of neu- $\beta$-gal-vWF was $62 \%$. However, neu- $\beta$-gal-vWF prepared in the presence of benzamidine, leupeptin, and aprotonin retained $99 \%$ of ristocetin cofactor activity, though the reduction in carbohydrate was as great as in the absence of these protease inhibitors (Tables I, II, and III).

Effect of plasmin on carbohydrate modified $v W F$. Carbohydrate modified vWF, but not native vWF, readily lost large multimers consequent to plasmin proteolysis. This was evident with neu-vWF, but even more so with neu- $\beta$-gal-vWF (Fig. 3). As little as $4 \mu \mathrm{g}$ plasmin/mg of vWF produced appreciable large multimer loss from neu- $\beta$-gal-vWF in $16 \mathrm{~h}$ (Fig. 4). This effect was dose dependent (Fig. 4). On the other hand, only minimal loss of large multimers from native vWF could be detected with $96 \mu \mathrm{g}$ of plasmin per mg of vWF after $24 \mathrm{~h}$ (not shown).

\section{Discussion}

Conflicting reports concerning the possible role of carbohydrate in the structure and function of vWF have led us to explore the effect of sequential enzymatic removal of carbohydrate 
Table III. Ristocetin Cofactor Activity of Carbohydrate Modified vWF

\begin{tabular}{|c|c|c|c|c|}
\hline Type of vWF & vWF antigen & Ristocetin cofactor & $\frac{\text { Ristocetin cofactor }}{\text { vWF antigen }}$ & $\begin{array}{l}\text { Ristocetin cofactor } \\
\text { remaining per } \mathrm{mg} \text { of } \mathrm{vWF}\end{array}$ \\
\hline & $U / m g$ & $U / m g$ & & $\%$ \\
\hline $\begin{array}{l}\text { Native } \\
\quad(9) \ddagger\end{array}$ & $\begin{array}{l}113 \quad 106^{*} \\
(101-121)\end{array}$ & $\begin{array}{l}125 \quad 118^{*} \\
(106-138)\end{array}$ & 1.10 & 100 \\
\hline $\begin{array}{l}\mathrm{Neu} \\
(8)\end{array}$ & $\begin{array}{l}105 \\
(100-110)\end{array}$ & $\begin{array}{l}130 \\
(108-145)\end{array}$ & 1.25 & 111 \\
\hline $\begin{array}{l}\text { Neu- } \beta \text {-gal } \\
\text { (4) }\end{array}$ & ${ }_{(90-111)}^{101} 107^{*}$ & $\begin{array}{ll}69 & 117^{*} \\
(52-79) & \end{array}$ & 0.68 & $6299^{*}$ \\
\hline $\begin{array}{l}\text { eF } \\
(8)\end{array}$ & $\begin{array}{l}105 \\
(101-110)\end{array}$ & $\begin{array}{l}103 \\
(72-125)\end{array}$ & 0.98 & 89 \\
\hline $\begin{array}{c}\text { eF-neu } \\
(7)\end{array}$ & $\begin{array}{l}101 \\
(91-112)\end{array}$ & $\begin{array}{l}78 \\
(45-122)\end{array}$ & 0.77 & 70 \\
\hline $\begin{array}{l}\text { eF-neu- } \beta \text {-gal } \\
\text { (3) }\end{array}$ & $\begin{array}{l}101 \\
(89-110)\end{array}$ & $\begin{array}{l}64 \\
(46-83)\end{array}$ & 0.63 & 57 \\
\hline
\end{tabular}

* These values were obtained when treatment with exoglycosidases was performed in the presence of benzamidine (20 mM), leupeptin (15 $\mu \mathrm{g} /$ $\mathrm{ml}$ ) and aprotonin $(20 \mathrm{U} / \mathrm{ml})$. $\ddagger$ Number of experiments indicated in parentheses.

from the molecule. In our hands, neuraminidase and neuraminidase followed by $\beta$-galactosidase removed similar percentages of sialic acid and D-galactose as previously reported by others $(9,10)$. In contrast to the recent report of Gralnik and co-workers (10), however, no discernible alteration of multimeric structure was observed after this treatment. Though exoglycosidase treatment of vWF in the absence of protease inhibitors was followed by a decrease in ristocetin cofactor

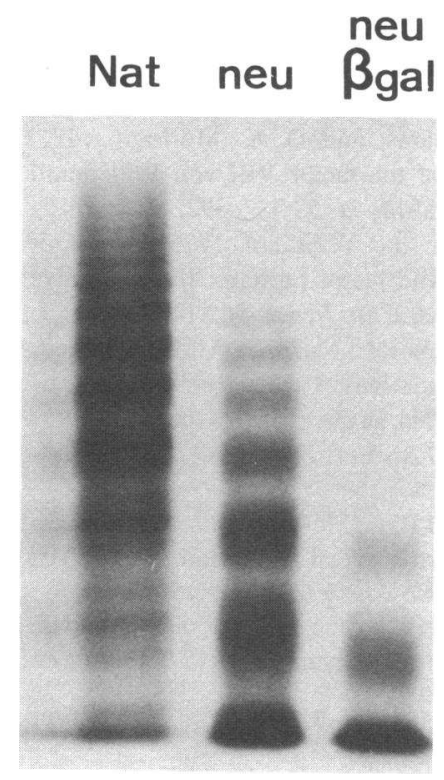

activity to $\sim 62 \%$ of the initial value, no decrease was seen when these inhibitors were present throughout the incubation. Nevertheless, the decrease in total hexose and galactose was the same in both cases. Gralnick et al. (10) and Sodetz et al. (9), on the other hand, reported a decrease in ristocetin cofactor activity to $10 \%$ of the initial value when vWF was

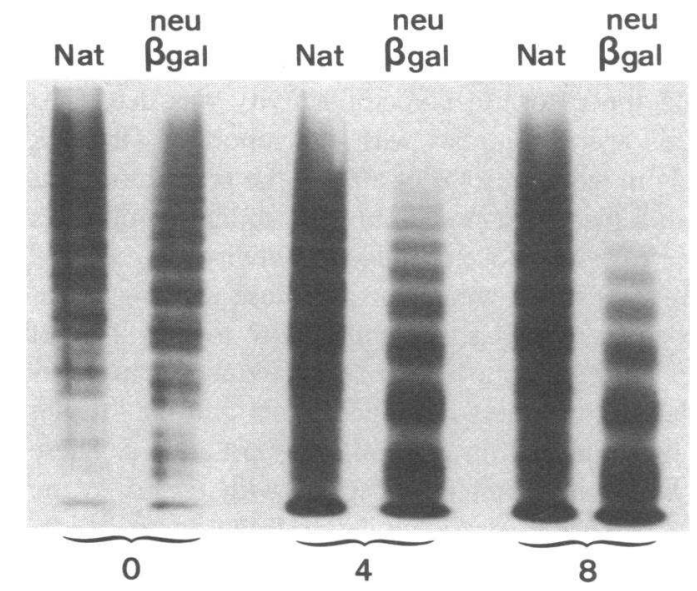

Figure 4. Effect of plasmin on multimeric structure of von Willebrand factor. SDS-1.4\% agarose electrophoresis of unreduced native vWF (Nat) and vWF sequentially treated with neuraminidase and $\beta$ galactosidase (neu- $\beta$-gal). After treatment with the exoglycosidases, the carbohydrate modified $\mathrm{vWF}$, and native vWF as a control, were incubated with plasmin at 4 or $8 \mu \mathrm{g} / \mathrm{mg}$ of vWF for $16 \mathrm{~h}$. On the left are shown these samples after incubation in the absence of plas$\min (0)$. 
treated with neuraminidase followed by $\beta$-galactosidase or galactose-oxidase. The explanation of these different results may lie in the demonstration that small quantities of plasmin induce loss of large multimers from carbohydrate modified vWF. Since traces of one or more proteases may contaminate even highly purified vWF, removal of carbohydrate may appear to be directly responsible for causing disaggregation of vWF when it is simply making the protein susceptible to attack by plasmin or other contaminating proteases. Disaggregation from any cause can be expected to decrease ristocetin cofactor activity. Though not readily apparent on SDS-agarose electrophoresis, some disaggregation may have occurred and caused the partial loss of ristocetin cofactor activity we observed in those of our experiments performed in the absence of protease inhibitors.

The physiological significance of the carbohydrate moiety of most glycoproteins is not known. Recently, however, carbohydrate has been shown to protect proteins from intracellular and extracellular proteolytic degradation (16). Our results demonstrate that this is clearly one role of the carbohydrate moiety of vWF. It may be particularly important in situations, such as intravascular coagulation, when free proteases may appear in plasma and degradation of vWF would significantly worsen an already compromised hemostatic mechanism.

Treatment of vWF with endo F removed $\sim 69 \%$ of total hexose and of D-galactose. This was associated with an alteration in the migration rate of the reduced subunit in SDS-polyacrylamide gels consistent with a decrease in molecular mass of approximately $10 \%$. Since all of the vWF subunit changed its migration rate after treatment, it is unlikely that carbohydrate was removed from only a subset of vWF molecules. In addition, all of the multimers of unreduced vWF showed a more rapid migration in SDS-agarose after treatment with endo F. However, there was no discernible loss of large multimers and the ristocetin cofactor activity was decreased only $11 \%$. This again contrasts with the report of Gralnick and co-workers in which release of $60 \%$ of the D-galactose was associated with a readily demonstrable loss of large multimers and a $70 \%$ decrease in ristocetin cofactor activity.

Treatment of eF-vWF with neuraminidase and $\beta$-galactosidase succeeded in reducing the total hexose to only $17 \%$ of that in native vWF. Despite this marked reduction in sugar content, the larger multimers remained intact and the "triplet structure" of repeating multimeric units was not altered. These observations have important implications with regard to the proposed role of carbohydrate in determining some of the abnormalities seen in von Willebrand disease (10). In a previous report we showed that the vWF in types I, IIA, and IIb von Willebrand disease had a normal or decreased isoelectric point (29). On the contrary, neuraminidase-treated vWF had a substantially higher isoelectric point than normal vWF (28), as would be expected following removal of the negatively charged sialic acid residues. It was, therefore, unlikely that simple absence of sialic acid was the basis for the vWF abnormalities seen in the von Willebrand disease variants studied. However, a more profound defect in the carbohydrate structure of $\mathrm{vWF}$ - with balancing effects on the isoelectric point-could not be excluded on the basis of those studies. The current results, however, are not consistent with the latter possibility. First, the multimeric structure of eF-neu- $\beta$-galvWF is intact with only $17 \%$ of the total hexose remaining. Moreover, removal of $69 \%$ of the total hexose with endo $F$ alone resulted in more rapid migration of all of the multimers without changing their triplet structure. Such an alteration in migration rate of individual multimers has not yet been seen in von Willebrand disease, including those variants in which the large multimers are lacking. Even those rare variants in which the triplet pattern is disordered do not show the changes seen here $(30,31)$. Though these considerations cannot exclude a subtle abnormality of carbohydrate in von Willebrand disease, they make a global disorder unlikely.

\section{Acknowledgments}

We wish to acknowledge Dr. Carolyn Orthner for providing cryoprecipitate; Dr. Gilbert Ashwell for the gift of $\beta$-galactosidase; Dr. Carol Fulcher and Dr. John Griffin for helpful criticism and discussion; Mr. Kevin Ferreri for the assays of amino sugars; and Ms. Claire Jackson for excellent secretarial assistance.

This work was supported in part by National Institutes of Health grants HL-15491, HL-30265, and HL-31950. This is publication 3353 IMM of the Scripps Clinic and Research Foundation.

\section{References}

1. Zimmerman, T. S., and Z. M. Ruggeri. 1983. von Willebrand's disease. In Clinics in Hematology. L. A. Harker and T. S. Zimmerman, editors. W. B. Saunders Co., Ltd., London. 12:175-200.

2. Ruggeri, Z. M., and T. S. Zimmerman. 1980. Variant von Willebrand's disease: characterization of two subtypes by analysis of multimeric composition of factor VIII/von Willebrand factor in plasma and platelets. J. Clin. Invest. 65:1318-1325.

3. Gralnick, H. R., S. B. Williams, and D. K. Morisato. 1981. Effect of the multimeric structure of the factor VIII/von Willebrand factor protein on binding to platelets. Blood. 58:387-397.

4. Gralnick, H. R., B. S. Coller, and Y. Sultan. 1975. Studies of the human factor VIII/von Willebrand factor protein. III. Qualitative defects in von Willebrand's disease. J. Clin. Invest. 56:814-827.

5. Debeire, P., J. Montreuil, B. Samor, C. Mazurier, M. Goudemand, H. Van Halbeek, and J. F. G. Vliegenthart. 1983. Structure determination of the major asparagine-linked sugar chain of human factor VIII-von Willebrand factor. FEBS (Fed. Eur. Biol. Soc.) Lett. 151:2225.

6. Sodetz, J. M., S. V. Pizzo, and P. A. McKee. 1977. Relationship of sialic acid to function and in vivo survival of human factor VIII/ von Willebrand factor protein. J. Biol. Chem. 252:5538-5546.

7. Rosenfeld, L., and E. P. Kirby. 1979. The effects of neuraminidase treatment on the biological activities of factor VIII. Thromb. Res. 15:255-261.

8. De Marco, L., and S. S. Shapiro. 1981. Properties of human 
asialo-factor VIII. A ristocetin-independent platelet-aggregating agent. J. Clin. Invest. 68:321-328.

9. Gralnick, H. R. 1978. Factor VIII/von Willebrand factor protein. Galactose, a cryptic determinant of von Willebrand factor activity. $J$. Clin. Invest. 62:496-499.

10. Sodetz, J. M., J. C. Paulson, S. V. Pizzo, and P. A. McKee. 1978. Carbohydrate on human factor VIII/von Willebrand factor. Impairment of function by removal of specific galactose residues. $J$. Biol. Chem. 253:7202-7206.

11. Gralnick, H. R., S. B. Williams, and M. E. Rick. 1983. Role of carbohydrate in multimeric structure of factor VIII/von Willebrand factor protein. Proc. Natl. Acad. Sci. (USA). 80:2771-2774.

12. Howard, M. A., J. Perkin, J. Koutts, and B. G. Firkin. 1981. Quantitation of binding of factor VIII antigen to Concanavalin A. Br. J. Haematol. 47:607-615.

13. Gralnick, H. R., M. C. Cregger, and S. B. Williams. 1982. Characterization of the defect of the factor VIII/von Willebrand factor protein in von Willebrand's disease. Blood. 59:542-548.

14. Zimmerman, T. S., R. Voss, and T. S. Edgington. 1979. Carbohydrate of the factor VIII/von Willebrand factor in von Willebrand's disease. J. Clin. Invest. 64:1298-1302.

15. Elder, J. H., and S. Alexander. 1982. endo- $\beta$-N-acetylglucosaminidase F: endoglycosidase from Flavobacterium meningosepticum that cleaves both high-mannose and complex glycoproteins. Proc. Natl. Acad. Sci. (USA). 79:4540-4544.

16. Bernard, B. A., K. M. Yamada, and K. Olden. 1982. Carbohydrates selectively protect a specific domain of fibronectin against proteases. J. Biol. Chem. 257:8549-8554.

17. Newman, J., A. J. Johnson, M. H. Karpatkin, and S. Puszkin. 1971. Methods for the production of clinically effective intermediateand high-purity factor-VIII concentrates. Br. J. Haematol. 21:1-20.

18. Switzer, M. E., and P. A. McKee. 1976. Studies on human antihemophilic factor. Evidence for a covalently linked subunit structure. J. Clin. Invest. 57:925-937.

19. Deutsch, D. G., and Metz, E. T. 1970. Plasminogen: Purification from human plasma by affinity chromatography. Science (Wash. DC). 170:1095-1096.

20. Dubois, M., K. A. Gilles, J. K. Hamilton, P. A. Rebers, and
F. Smith. 1956. Colorimetric method for determination of sugars and related substances. Anal. Chem. 28:350-356.

21. Warren, L. 1959. The thiobarbituric acid assay of sialic acids. J. Biol. Chem. 234:1971-1975.

22. Finch, P. R., R. Yuen, H. Schachter, and M. A. Moscarello. 1969. Enzymatic methods for the micro assay of D-mannose, Dglucose, D-galactose and L-fucose from acid hydrolyzates of glycoproteins. Anal. Biochem. 31:296-305.

23. Lowry, O. H., N. J. Rosebrough, A. L. Farr, and R. J. Randall. 1951. Protein measurement with the folin phenol reagent. J. Biol. Chem. 193:265-275.

24. Laemmli, U. K. 1970. Cleavage of structural proteins during the assembly of the head of bacteriophage T4. Nature (Lond.). 227:680685.

25. Ruggeri, Z. M., and T. S. Zimmerman. 1981. The complex multimeric composition of factor VIII/von Willebrand factor. Blood. 57:1140-1143.

26. Ruggeri, Z. M., P. M. Mannucci, R. Bader, and T. Barbui. 1978. Factor VIII-related properties in platelets from patients with von Willebrand's disease. J. Lab. Clin. Med. 91:132-140.

27. Zimmerman, T. S., and J. R. Roberts. 1980. Factor VIII related antigen. In Immunoassays: Clinical Laboratory Techniques for the 1980s. R. M. Nakamura, W. R. Dito, and E. S. Tucker III, editors. Alan R. Liss, Inc., New York. 4:339-349.

28. Burnette, W. N. 1981. "Western Blotting": Electrophoretic transfer of proteins from sodium dodecyl sulfate-polyacrylamide gels to unmodified nitrocellulose and radiographic detection with antibody and radioiodinated protein a. Anal. Biochem. 112:195-203.

29. Fulcher, C. A., Z. M. Ruggeri, and T. S. Zimmerman. 1983. Isoelectric focusing of human von Willebrand factor in urea-agarose gels. Blood. 61:304-310.

30. Ruggeri, Z. M., I. M. Nilsson, R. Lombardi, L. Holmberg, and T. S. Zimmerman. 1982. Aberrant multimeric structure of von Willebrand factor in a new varient of von Willebrand's disease (Type IIC). J. Clin. Invest. 70:1124-1127.

31. Kinoshita, S., J. Harrison, J. Lazerson, and C. F. Abildgaard. 1984. A new variant of dominant Type II von Willebrand's disease with aberrant multimeric pattern of Factor VIII-related antigen (Type IID). Blood. 63:1369-1371. 